\title{
Preoperative Tim-3 expression on peripheral NK cells is correlated with pathologic TNM staging in colorectal cancer
}

\author{
YANG WANG $^{1}$, JINTANG SUN $^{1}$, WENJUAN GAO ${ }^{1}$, BINGFENG SONG $^{1}$, \\ QIANQIAN SHAO ${ }^{1}$, LEI ZHAO $^{1}$, YUN ZHANG $^{1}$, QINGJIE WANG $^{1}$, YUN ZHANG $^{2}$ and XUN QU ${ }^{1}$ \\ ${ }^{1}$ Department of Tumor Immunity, Institute of Basic Medical Sciences; ${ }^{2}$ The Key Laboratory of Cardiovascular Remodeling \\ and Function Research, Chinese Ministry of Education and Chinese Ministry of Health, \\ Qilu Hospital of Shandong University, Jinan, Shandong 250012, P.R. China
}

Received February 20, 2016; Accepted February 9, 2017

DOI: $10.3892 / \mathrm{mmr} .2017 .6482$

\begin{abstract}
Previous research has indicated that T cell immunoglobulin and mucin domain 3 (Tim-3) serves an important regulatory role in lymphocytes and in several cancers. However, the association between Tim-3 expression on various lymphocyte subsets and human colorectal cancer (CRC) has not been elucidated. The present study aimed to characterize Tim-3 expression on peripheral lymphocytes, including cluster of differentiation $\mathrm{CD}^{+}{ }^{+} \mathrm{CD} 56^{-} \mathrm{T}$ cells, CD $3^{-\mathrm{CD}} 56^{+}$natural killer (NK) cells and $\mathrm{CD}^{+}{ }^{+} \mathrm{CD} 56^{+}$natural killer $\mathrm{T}(\mathrm{NKT})$ cells, in patients with CRC. The frequency of T cells, NK cells and NKT cells expressing Tim-3 was assessed by multicolor flow cytometry of peripheral blood collected from 36 preoperative CRC patients and 38 healthy donors. The expression of Tim-3 on lymphocyte subsets from 53 postoperative blood samples of CRC patients was also analyzed. There were fewer circulating NK cells in patients with CRC compared with healthy controls $(\mathrm{P}=0.0027)$; NK cell expression of Tim-3 was also significantly decreased $(\mathrm{P}=0.0239)$. The frequency of circulating NK cells and Tim $-3^{+} \mathrm{NK}$ cells was negatively correlated with clinical cancer stage, compared with healthy controls, but not with other clinicopathological parameters or serum concentrations of CRC biomarkers. Furthermore, the expression of Tim-3 in NK cells was higher in CRC patients without metastasis. Notably, NK cell Tim-3 expression in CRC patients was significantly restored following surgical resection of the primary tumor. In conclusion, the present study indicates the presence of an altered frequency and expression of Tim-3 in peripheral NK cells in CRC patients. Preoperative
\end{abstract}

Correspondence to: Professor Xun Qu or Dr Jintang Sun, Department of Tumor Immunity, Institute of Basic Medical Sciences, Qilu Hospital of Shandong University, 107 West Wenhua Road, Jinan, Shandong 250012, P.R. China

E-mail: quxun@sdu.edu.cn

E-mail: sunjintang003@163.com

Key words: T cell immunoglobulin and mucin domain 3, colorectal cancer, natural killer cells, metastasis, tumor node metastasis stage
Tim-3 expression on peripheral NK cells is correlated with differential staging in colorectal cancer, and may be useful as a serum biomarker.

\section{Introduction}

Recent advances in immunology and molecular biology have demonstrated the important role served by the immune system in cancer development (1). Patients with colorectal cancer (CRC), which is the fourth most frequently diagnosed cancer and the second leading cause of cancer-associated mortality in the United States, exhibit weakened immune responses (2). Immune infiltrates in CRC are of clinical importance; they may aid the prediction of metastatic invasion and possibly clinical outcome $(3,4)$. Furthermore, certain studies have suggested that aberrations of local immune infiltrations and circulating lymphocyte subsets may have clinical significance $(5,6)$. Therefore, several studies are currently investigating the value of specific complementary and non-invasive biomarkers for use in CRC diagnosis, which may also improve cost-benefit ratio (7). Peripheral blood mononuclear cells (PBMCs) represent a reservoir of inflammatory cells that contribute to the progression of various diseases $(8,9)$, and the characterization of CRC patients based on lymphocyte imbalances, such as a reduced cluster of differentiation $(\mathrm{CD}) 4^{+} / \mathrm{CD} 8^{+}$ratio (10) and an enrichment of regulatory $\mathrm{T}$ cells (11), has previously been reported.

Previous research has demonstrated that $\mathrm{T}$ cell expression of programmed death-1 (PD-1) and T cell immunoglobulin and mucin protein-3 (Tim-3) can induce T cell exhaustion in CRC patients $(12,13)$. Tim-3 has been reported to have a critical role in regulating the immune response against viral infection and carcinoma. Furthermore, there is growing evidence that Tim-3 may function as a regulator of the anti-tumor immune response and the development of cancer (14). Previous research has suggested that $\mathrm{PD}-1^{\text {hi }}$ Tim $-3^{+}$T cells are strongly associated with post-transplantation leukemia relapse in patients with acute myelocytic leukemia (15). Furthermore, levels of Tim-3 were significantly increased on $\mathrm{CD}^{+} \mathrm{T}$ cells and $\mathrm{CD}^{+} \mathrm{T}$ cells, and were associated with higher cancer stages in renal cell carcinoma (16). Unregulated Tim-3 expression in natural killer (NK) cells is associated with disease 
stage, and predicts a poorer prognosis, in melanoma (17) and lung adenocarcinoma (18). However, there is limited data on Tim-3 expression in the peripheral lymphocytes of patients with CRC.

The present study determined the frequency of $\mathrm{CD}^{+} \mathrm{CD} 56$ $\mathrm{T}$ cells, $\mathrm{CD} 3{ }^{-} \mathrm{CD} 56^{+} \mathrm{NK}$ cells and $\mathrm{CD}^{+} \mathrm{CD} 56^{+}$natural killer $\mathrm{T}$ (NKT) cells expressing Tim-3 in the peripheral blood of preoperative CRC patients. The expression of Tim-3 in lymphocyte subsets from postoperative blood samples of patients with $\mathrm{CRC}$ was also investigated. The results were correlated with the clinicopathological parameters of the patients. Decreased Tim-3 expression on NK cells significantly correlated with tumor node metastasis (TNM) stage. Furthermore, Tim-3 expression rapidly recovered to baseline levels post-surgery. These results may be useful in targeting specific cell types, and may provide valuable information in the prediction of tumor progression.

\section{Materials and methods}

Participants. Chinese individuals (n=127) including 89 CRC patients and 38 age- and gender-matched healthy volunteers [healthy control group (HC)] were recruited from Qilu Hospital of Shandong University (Jinan, China), during May-October 2013. Basic patient information, clinical data and laboratory results, including serum concentration of three CRC biomarkers [carcinoembryonic antigen (CEA), cancer antigen 199 (CA199) and cancer antigen 724 (CA724)] were retrieved from the medical records for each patient. An experienced pathologist reviewed the histopathological criteria, including the tumor differentiation and TNM stage. $\mathrm{HC}$ individuals had no abnormal laboratory results and no family history of autoimmune diseases. The demographic and clinicopathological characteristics of the patients with CRC and HCs are presented in Table I. The Qilu Hospital of Shandong University ethics committee approved the study, and written informed consent was acquired from each participant. Peripheral blood samples were obtained from the participants and processed within $6 \mathrm{~h}$.

Flow cytometry. PBMCs were obtained by centrifugation with Ficoll-Paque Plus (GE Healthcare Life Sciences, Chalfont, UK). PBMC staining for flow cytometry analysis was performed using the following fluorochrome-conjugated monoclonal antibodies: CD3-peridinin chlorophyll protein-Cy5 (555334), CD56-flourescein isothiocyanate (340410) and Tim-3-phycoerythrin (565570) (BD Biosciences, San Jose, CA, USA), according to the manufacturer's protocol. The peripheral blood was incubated with anti-CD3, anti-CD56 and anti-Tim-3 for $20 \mathrm{~min}$ at $4^{\circ} \mathrm{C}$ in the dark. An isotype control was performed alongside the test antibodies. Three-color FACS Calibur (BD Biosciences, San Jose, CA, USA) analysis was used to investigate Tim-3 expression and calculate mean fluorescence intensity (MFI) on $\mathrm{CD}^{+}{ }^{+} \mathrm{CD} 56^{-}$ $\mathrm{T}$ cells, $\mathrm{CD}^{-} \mathrm{CD}^{-} 6^{+} \mathrm{NK}$ cells and $\mathrm{CD}^{+}{ }^{+} \mathrm{CD} 56^{+} \mathrm{NKT}$ cells.

Statistical analysis. All data were analyzed using GraphPad Prism 5.0 software (GraphPad Software, Inc. La Jolla, CA, USA). Paired data within donors were analyzed using a paired Student's t-test. Unpaired data, between healthy and CRC patients, were analyzed using an unpaired Student's t-test.
Table I. Demographic and clinicopathological parameters of $\mathrm{CRC}$ patients and $\mathrm{HC}$ volunteers participating in the study.

A, CRC patients $(n=89)$

\begin{tabular}{|c|c|}
\hline Clinical parameter & Value \\
\hline \multicolumn{2}{|l|}{ Gender } \\
\hline Male & 56 \\
\hline Female & 33 \\
\hline Age (years) & $59(24-80)$ \\
\hline \multicolumn{2}{|l|}{ Lesion location } \\
\hline Rectum & 47 \\
\hline Colon & 42 \\
\hline \multicolumn{2}{|l|}{ Surgery } \\
\hline No & 36 \\
\hline Yes & 53 \\
\hline \multicolumn{2}{|l|}{ Pathological type } \\
\hline Adenocarcinoma & 80 \\
\hline Other or unclear & 9 \\
\hline \multicolumn{2}{|c|}{ Tumor differentiation } \\
\hline Well & 15 \\
\hline Median & 48 \\
\hline Poor & 19 \\
\hline Unclear & 7 \\
\hline \multicolumn{2}{|c|}{ Lymph node metastasis } \\
\hline Absent & 52 \\
\hline Present & 30 \\
\hline Unclear & 7 \\
\hline \multicolumn{2}{|l|}{ TNM stage } \\
\hline I & 5 \\
\hline II & 42 \\
\hline III & 27 \\
\hline IV & 15 \\
\hline
\end{tabular}

$\mathrm{B}, \mathrm{HC}$ volunteers $(\mathrm{n}=38)$

\begin{tabular}{lc} 
Clinical parameter & Value \\
\hline Gender & \\
Male & 22 \\
Female & 16 \\
Age (years) & $52.5(22-85)$
\end{tabular}

Values are presented as the number of patients/volunteers or the mean age of each group (with age range). CRC, colorectal cancer; HC, healthy control; TNM, tumor node metastasis.

Comparison of Tim-3 expression based on demographic and clinical parameters was performed using an unpaired t-test to compare two groups, and one-way analysis of variance to compare more than two groups, followed by Tukey's test. Spearman's rank correlation analysis was used to calculate the correlation coefficient. $\mathrm{P}<0.05$ was considered to indicate a statistically significant difference. 
A
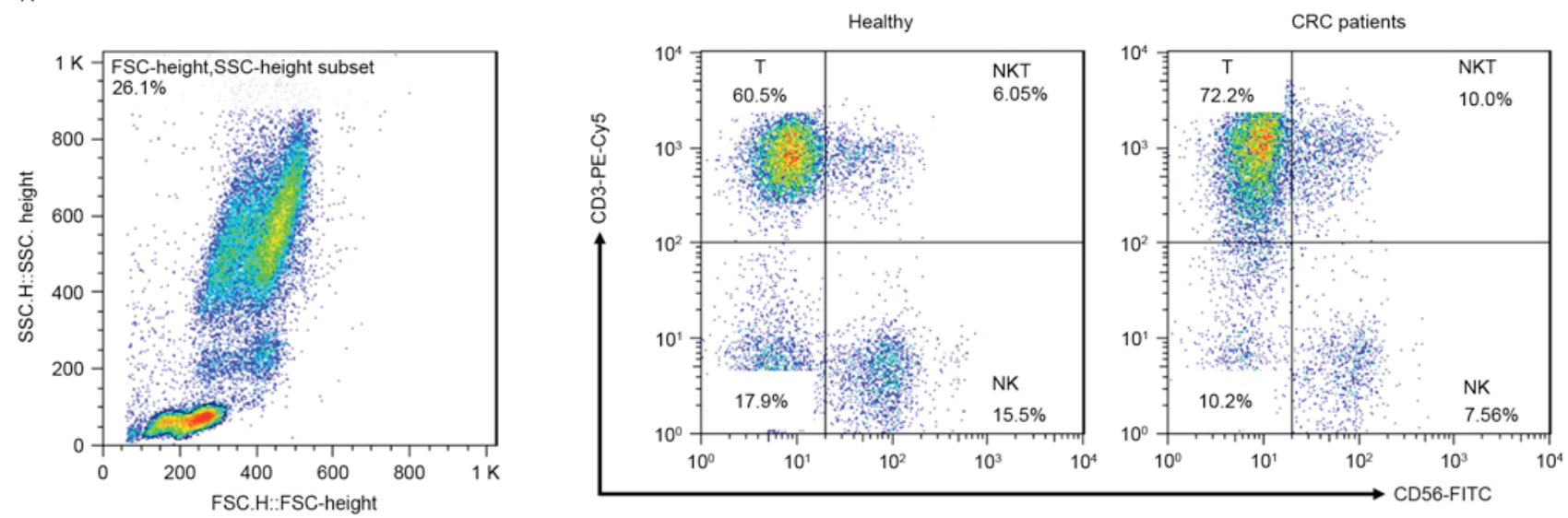

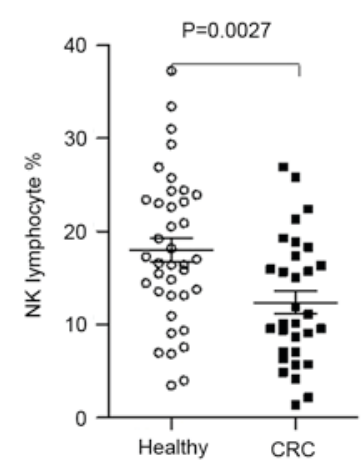

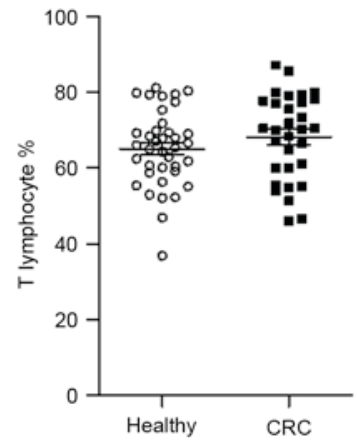

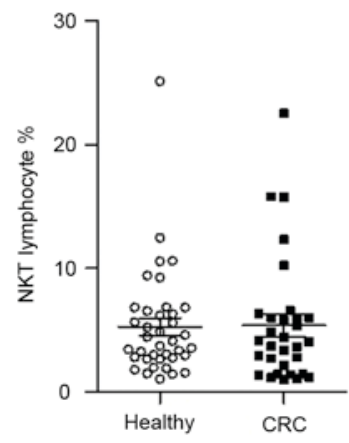

Figure 1. Decreased numbers of NK cells in lymphocytes from untreated CRC patients. Flow cytometry was used to identify CD3 ${ }^{+} \mathrm{CD} 56^{-} \mathrm{T}^{-}$cells, $\mathrm{CD}^{-} \mathrm{CD}^{-} 6^{+}$ $\mathrm{NK}$ cells and $\mathrm{CD}^{+} \mathrm{CD} 6^{+} \mathrm{NKT}$ cells from peripheral blood mononuclear cells isolated from healthy controls and untreated CRC patients. (A) Harvested cells were initially gated using live lymphocytes and subsequently on $\mathrm{CD}^{+} \mathrm{CD} 56^{-}, \mathrm{CD} 3^{-} \mathrm{CD} 56^{+}$and $\mathrm{CD}^{+} \mathrm{CD} 56^{+}$cells with $\geq 30,000$ events analyzed for each sample. (B) NK, (C) T and (D) NKT cells in CRC patients and HCs. Data points represent the T cell, NK cell and NKT cell percentages. NK, natural killer; CRC, colorectal cancer; CD, cluster of differentiation; NKT, NK T cells; FITC, fluorescein isothiocyanate; PE, phycoerythrin; FSC, forward scatter; SSC, side scatter.

\section{Results}

Characteristics of the study population. The distribution of selected clinicopathological features of the CRC patients and $\mathrm{HC}$ volunteers are presented in Table I. Amongst $89 \mathrm{CRC}$ cancer patients, $47(52.8 \%)$ cases were classified as rectal cancer and $42(47.2 \%)$ as colon cancer. Most CRC patients (89.9\%) were histologically confirmed as adenocarcinoma, with the remaining $9(10.1 \%)$ patients classified as 'other carcinoma'. A total of $53(59.6 \%)$ patients had previously undergone surgery. TNM staging, which was performed according to guidelines set out by The Union for International Cancer Control/American Joint Committee on Cancer TNM Classification (7th edition) (19), classified 49 CRC patients $(52.8 \%)$ as stage I-II, and $42 \mathrm{CRC}$ patients $(47.2 \%)$ as stage III-IV.

Levels of lymphocyte subsets in CRC patients and HC. The percentage of T cells, NK cells and NKT cells were investigated in peripheral blood from preoperative CRC patients and $\mathrm{HC}$ volunteers. The gating strategy used to distinguish the various lymphocyte populations is depicted in Fig. 1A. Compared with healthy individuals, the percentage of circulating NK cells in CRC patients was significantly decreased (12.34 \pm 6.77 vs. $17.98 \pm 8.02 \%, P=0.0027$;
Fig. 1B). The levels of T cells and NKT cells from preoperative CRC patients and healthy controls demonstrated no significant difference $(68.24 \pm 11.27$ vs. $65.14 \pm 10.10 \%$, and $5.42 \pm 5.05$ vs. $5.28 \pm 4.35 \%, \mathrm{P}>0.05$; Fig. $1 \mathrm{C}$ and D). These results demonstrated that the level of NK cells was reduced in CRC patients.

Tim-3 expression is decreased on peripheral NK cells in CRC patients. Abnormal expression of Tim-3 on innate immune cells has been associated with the progression of several clinical diseases, such as infection, immune diseases and tumors $(20,21)$. To further define the Tim-3 expression profile on various lymphocyte subtypes between the two patient groups, flow cytometric analysis of the Tim-3 expression profile was performed on peripheral blood from preoperative CRC patients $(n=36)$ and HCs (Fig. 2A). Overall, the median expression of Tim-3 was higher on NK cells compared with NKT cells and T cells. Furthermore, Tim $-3^{+}$NK cells were significantly decreased in CRC cases compared with $\mathrm{HCs}$ (71.51 \pm 17.39 vs. $81.14 \pm 17.07 \%, \mathrm{P}=0.0239$; Fig. $2 \mathrm{~B})$, however the percentage of Tim-3 expressing T cells and NKT cells from CRC patients and healthy controls demonstrated no significant difference. These results indicated that Tim-3 may be involved in the immune dysfunction of CRC, via an NK cell-mediated role. 

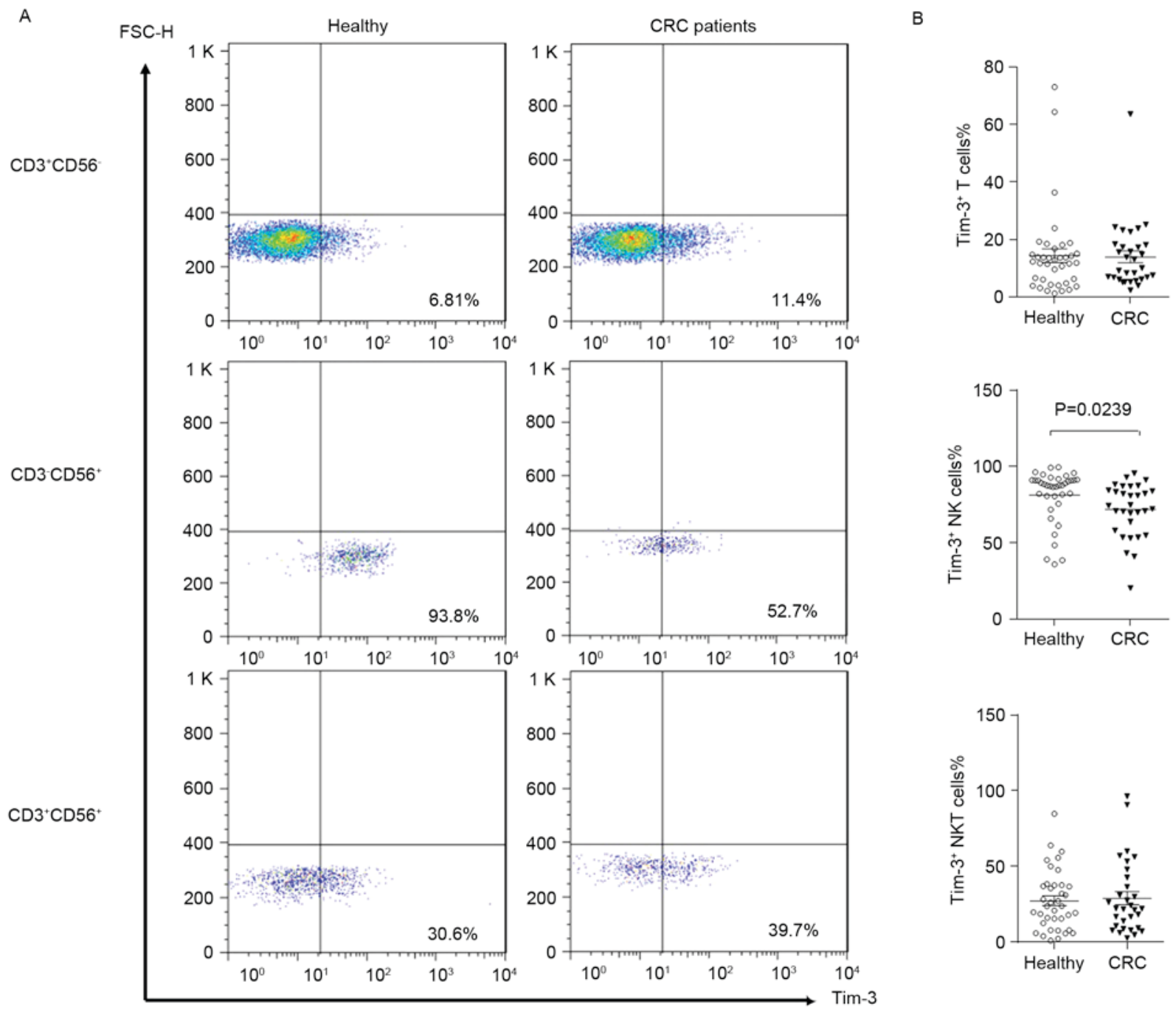

Figure 2. Tim- $3^{+}$lymphocyte frequencies. The number of Tim- $3^{+} \mathrm{NK}$ cells was reduced in CRC patients. (A) Harvested cells were initially gated for CD $3^{+} \mathrm{CD} 56$, $\mathrm{CD} 3{ }^{-} \mathrm{CD} 56^{+}, \mathrm{CD}^{+} \mathrm{CD}^{2} 6^{+}$lymphocytes, and then for Tim- $3^{+}$cells with $\geq 30,000$ events analyzed in each sample. Data are representative results from different groups of subjects, and the percentage of Tim $-3^{+}$lymphocyte subsets from individual subjects are presented. (B) Summarized data demonstrate the percentage of Tim- $3^{+}$lymphocytes. The median is represented by a horizontal line. Tim-3, T cell immunoglobulin and mucin protein-3; NK, natural killer; CRC, colorectal cancer; CD, cluster of differentiation; NKT, NK T cells; FSC, forward scatter.

Reductions in NK cells and Tim- $3^{+} \mathrm{NK}$ cells are correlated with TNM stage. The percentage of NK and Tim- $3^{+} \mathrm{NK}$ cells was correlated with various clinicopathological features (Tables II and III). Associations between the percentage of NK cells or Tim- $3^{+}$NK cells with TNM stage were assessed by Spearman's rank correlation (Fig. 3A and B). Patients with stage I and II CRC were pooled in this analysis, due to the limited number of patients assessed with stage I CRC. Overall, NK cells demonstrated the most significant reduction with disease stage. Furthermore, significantly decreased numbers of NK cells and Tim- $3^{+}$NK cells were observed in CRC patients with stage IV disease, compared with $\mathrm{HCs}(\mathrm{P}<0.05)$. Notably, the percentage of Tim- $3^{+}$NK cells was decreased at stage IV, compared with stages I-II and III.

Preoperative CRC patients were subsequently classified as non-metastatic $(n=30)$ or metastatic $(n=6)$. Patients with stage I/II/III cancer demonstrated the highest percentage of NK cells, and this was statistically significant when compared with the metastatic stage IV group $(13.81 \pm 6.631 \mathrm{vs}$. $6.252 \pm 2.900 \%, P=0.0014$; Fig. 3C). Furthermore, a significant difference was observed in the percentage of Tim $-3^{+} \mathrm{NK}$ cells in non-metastatic patients compared with metastatic groups ( $77.01 \pm 16.02$ vs. $59.48 \pm 15.32 \%, P=0.0218$; Fig. $3 \mathrm{D})$. There were no significant differences in the percentage of Tim- $3^{+} \mathrm{T}$ cells or Tim- $3^{+}$NKT cells (data not shown). Several patients with non-metastatic disease appear to maintain a higher NK Tim-3 expression; therefore these data suggested that Tim-3 may be a useful indicator of CRC disease progression, however a larger cohort of patients are required to further investigate this hypothesis.

Effects of surgical resection on Tim-3 expression. To investigate the impact of surgical resection on lymphocyte number and Tim-3 expression, postsurgical blood was collected from $\mathrm{CRC}$ patients that had undergone surgery $(\mathrm{n}=53)$. Blood samples were collected within 1 week of surgery, and these included 28 cases with stage I/II and 25 cases with stage III/IV. The results indicated no difference in the percentage of lymphocyte subtypes between the two patient groups (Fig. 4A), however, the percentage of Tim $-3^{+} \mathrm{NK}$ cells, but not the MFI of Tim- 3 on 
Table II. Association between percentage of NK cells and clinicopathological features in patients with colorectal cancer.

\begin{tabular}{lcc}
\hline Clinical feature & $\begin{array}{c}\text { Median NK cells, } \% \\
\text { (range) }\end{array}$ & P-value \\
\hline Gender & & 0.5945 \\
$\quad$ Male & $9.76(1.39-26.91)$ & \\
Female & $11.89(4.14-25.83)$ & \\
Age & $10.11(1.39-26.91)$ & 0.7732 \\
Lesion location & & 0.8359 \\
$\quad$ Rectum & $11.50(1.39-26.91)$ & \\
$\quad$ Colon & $9.56(4.14-25.83)$ & \\
Tumor differentiation & & 0.6745 \\
$\quad$ Well & $11.89(8.64-22.39)$ & \\
$\quad$ Median & $11.10(1.39-26.91)$ & \\
Poor & $9.56(4.14-19.25)$ & \\
Lymph node metastasis & & 0.1802 \\
$\quad$ Absent & $10.11(1.39-25.83)$ & \\
Present & $16.87(5.64-26.91)$ & \\
\hline
\end{tabular}

Student's t-test or analysis of variance was used to compare the percentage of NK cells with patient gender, lesion location, tumor differentiation and lymph node status. Spearman's rank correlation analysis was used to evaluate the association between the percentage of NK cells and patient age. NK, natural killer.

NK cells, was significantly higher in patients that had received surgery, compared with preoperative patients $(84.31 \pm 13.55$ vs. $71.51 \pm 17.39 \%, \mathrm{P}=0.0003$; Fig. 4B).

To further investigate the impact of surgery on lymphocyte populations, pre- and post-surgical blood samples were obtained from 7 patients. No significant difference was observed in the percentage of lymphocytes ( $\mathrm{P}>0.05$; Fig. 5A). However, surgery elevated Tim- 3 expression on NK cells to the baseline levels observed in healthy controls, in the majority of patients with reduced pre-surgical levels $(\mathrm{P}=0.0126$; Fig. 5B). No significant difference was observed in the Tim-3 MFI in NK cells, or in the levels of Tim-3 expression on T cells and NKT cells ( $P>0.05$; data not shown). These data suggest that Tim-3-expressing NK cells are more prevalent following resection of the primary tumor.

NK cells and Tim- $3^{+}$NK cells are not associated with CA199, CEA or CA724. The association of NK cells and Tim- $-3^{+} \mathrm{NK}$ cells with the preoperative serum concentration of three CRC biomarkers was assessed. A weak negative association was observed between the percentage of NK cells and the concentration of CA199, however this did not reach significance $\left(\mathrm{R}^{2}=0.1223, \mathrm{P}=0.0538\right.$; Fig. 6A). No correlation was observed between the percentage of NK cells and the concentration of CEA $\left(\mathrm{R}^{2}=0.0100\right.$; Fig. 6B) or CA724 $\left(\mathrm{R}^{2}=0.000\right.$; Fig. $\left.6 \mathrm{C}\right)$. Furthermore, there appeared to be a weak negative correlation between Tim- $3^{+} \mathrm{NK}$ cells and the serum concentration of CA199 $\left(\mathrm{R}^{2}=0.030\right.$; Fig. 6D), CEA $\left(\mathrm{R}^{2}=0.088\right.$; Fig. 6E) and CA724 $\left(R^{2}=0.0086\right.$; Fig. $\left.6 \mathrm{~F}\right)$, however these were not significant ( $\mathrm{P}>0.05$ for all cases).
Table III. Association between the percentage of Tim- $3^{+}$ NK cells and clinicopathological features in patients with colorectal cancer.

\begin{tabular}{lcc}
\hline Clinical feature & $\begin{array}{c}\text { Median Tim- } 3^{+} \mathrm{NK} \\
\text { cells, \% (range) }\end{array}$ & P-value \\
\hline Gender & & 0.3133 \\
$\quad$ Male & $71.25(20.44-91.04)$ & \\
$\quad$ Female & $80.57(43.29-95.40)$ & \\
Age & $74.1(20.44-95.40)$ & 0.8068 \\
Lesion location & & 0.7739 \\
$\quad$ Rectum & $80.62(20.44-92.68)$ & \\
$\quad$ Colon & $70.21(53.65-95.40)$ & \\
Tumor differentiation & & 0.9197 \\
$\quad$ Well & $80.57(20.44-100)$ & \\
$\quad$ Median & $74.49(41.01-92.68)$ & \\
$\quad$ Poor & $70.60(53.65-84.20)$ & \\
$\quad$ Lymph node metastasis & & 0.9889 \\
$\quad$ Absent & $80.57(20.44-95.40)$ & \\
Present & $72.54(53.00-91.04)$ & \\
\hline
\end{tabular}

Student's t-test or analysis of variance was used to compare the percentage of Tim- $3^{+}$NK cells with patient gender, lesion location, tumor differentiation and lymph node status. Spearman's rank correlation analysis was used to evaluate the association between the percentage of Tim- $3^{+}$NK cells and patient age. Tim-3, T cell immunoglobulin and mucin protein-3; NK, natural killer.

\section{Discussion}

The peripheral blood from cancer patients contains a reservoir of cells and cell products derived from the primary tumor and distant metastases, which may contain valuable diagnostic or prognostic information. The collection of blood samples is also minimally invasive, and this resource has the potential for wide-scale use in CRC biomarker screening. Considering the convenience of peripheral blood biomarker detection and the influence of Tim-3 on immune cell function, it would be valuable to investigate the mechanistic role of Tim-3 as a potential biomarker in the progression of CRC. The present study used peripheral blood samples to more precisely characterize the expression of Tim-3 on lymphocytes, in response to CRC. The percentage of total $\mathrm{NK}$ and $\mathrm{Tim}-3^{+} \mathrm{NK}$ cells was significantly downregulated in patients with CRC; these NK cells would normally participate in a typical immune response. Notably, TNM stage was associated with the expression of Tim-3 on NK cells; the presence of Tim $-3^{+}$NK cells was significantly lower in patients with stage IV tumors, suggesting a possible association between Tim-3 expression and CRC metastasis. Furthermore, a previously unreported rebound in Tim-3 expression in NK cells was observed following surgical resection of the primary tumor. Distant metastasis is a critical event that impacts on the prognosis of patients with CRC. The present study indicated that patients with distant metastases had a significantly lower proportion of NK cells and Tim- $3^{+}$ NK cells, compared with patients without metastases. These 
A

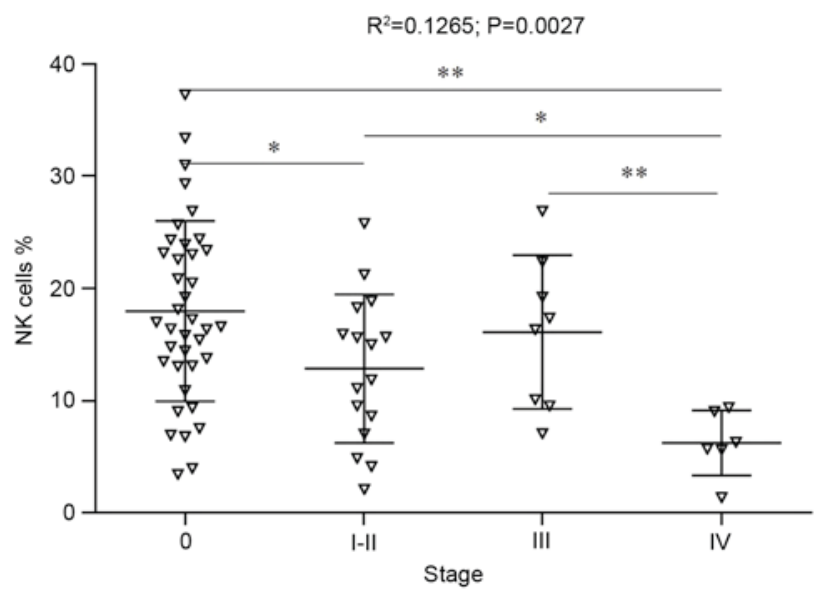

$\mathrm{C}$

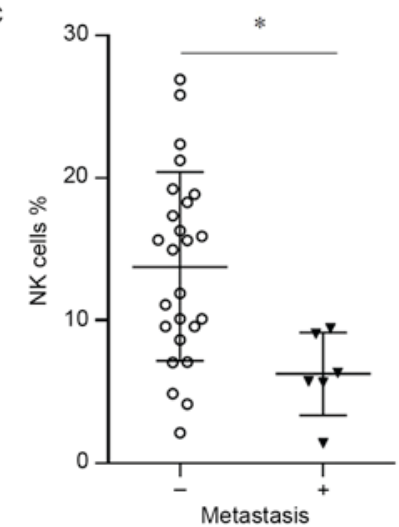

B

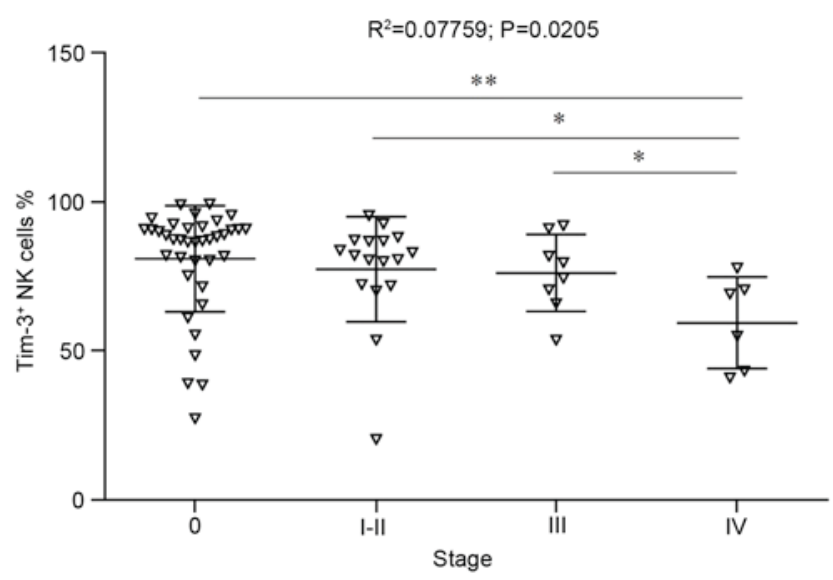

D

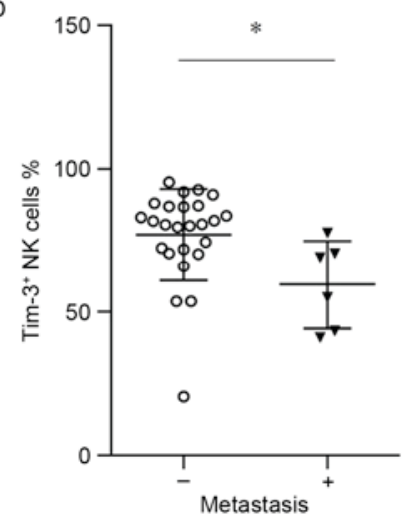

Figure 3. NK cells and Tim- $3^{+}$NK cells are associated with TNM stage. The association of (A) NK cells or (B) Tim- $3^{+}$NK cell percentage was correlated with TNM stage. Healthy individuals were designated as stage 0 , and patients were staged (I-IV) post surgery. Probability and $\mathrm{R}^{2}$ values were calculated for the entire data set by Spearman's rank correlation. Differences between healthy donors and patients at each disease stage were calculated by an unpaired Wilcoxon rank-sum test. " $\mathrm{P}<0.05$ and ${ }^{* *} \mathrm{P}<0.001$, vs. stage 0 , I-II or III as indicated in the figure. (C) The frequency of CD56 ${ }^{+} \mathrm{CD} 3^{-} \mathrm{NK}$ cells and (D) Tim-3 ${ }^{+} \mathrm{NK}$ cells was higher in CRC patients with metastasis, compared with CRC patients without metastasis. "P<0.05, vs. non-metastatic patients. Each symbol represents a single subject; the median value is indicated by a horizontal line. NK, natural killer; Tim-3, T cell immunoglobulin and mucin protein-3; TNM, tumor node metastasis; CRC, colorectal cancer; CD, cluster of differentiation; NKT, NK T cells.

results therefore indicated that Tim $-3^{+} \mathrm{NK}$ cells may serve a role in disease progression.

Poor cytotoxic activity of peripheral NK cells has been associated with an increased risk of cancer (22). Furthermore, NK cell infiltration in tumor tissue predicts improved prognosis, particularly in CRC $(23,24)$. In light of this research, NK cells have since been targeted as a potential cancer therapeutic (25). Tim-3 is constitutively expressed at high levels on resting NK cells (26), however, research regarding the function of Tim-3 on NK cells is conflicting. One study indicated that Tim-3 may deliver inhibitory signals and inhibit normal NK cell-mediated cytotoxicity (26), whereas another study suggested that Tim-3 may act as an activated receptor, where exposure to galectin- 9 results in enhanced interferon $-\gamma$ production by $\mathrm{Tim}-3^{+} \mathrm{NK}$ cells (27). Previous research has demonstrated that the number of NK cells is significantly reduced in CRC patients compared with healthy controls (28), which is consistent with the findings of the current study. These results indicate that NK cell function is damaged in patients with CRC, and an improved understanding of Tim-3 function, in the context of carcinogenesis and tumor development, may prove useful in the development of future therapeutics. Dysregulation of Tim-3 expression on NK cells is a feature of several diseases, with upregulation observed in advanced melanoma (17), hepatitis- $C$ infection (20) and lung cancer (29), and downregulation observed in human immunodeficiency virus infection (30). To our knowledge, this is the first report of a decreased proportion of Tim $-3^{+} \mathrm{NK}$ cells in patients with $\mathrm{CRC}$, a scenario that is compatible with Tim-3's role as an activated receptor on normal NK cells. Furthermore, the reduction in Tim-3 expression was associated with a loss of Tim-3-expressing cells, because patients undergoing surgery demonstrated no significant attenuation in the mean fluorescence intensity of Tim-3, compared with untreated patients (data not shown). In CRC patients, serum CEA, CA199 and CA724 may be useful in the diagnosis of colorectal carcinoma $(31,32)$. The relationship between the proportion of $\mathrm{CD} 3{ }^{-} \mathrm{CD} 56^{+} \mathrm{NK}$ cells in CRC patients and these serum biomarkers was investigated. Although there appeared to be an association between serum CA199 levels and the proportion of CD3 ${ }^{-}$CD56 ${ }^{+} \mathrm{NK}$ cells in CRC patients, this did not reach statistical significance.

One approach to activating an anti-tumor immune response, which is at the forefront of current cancer 
A
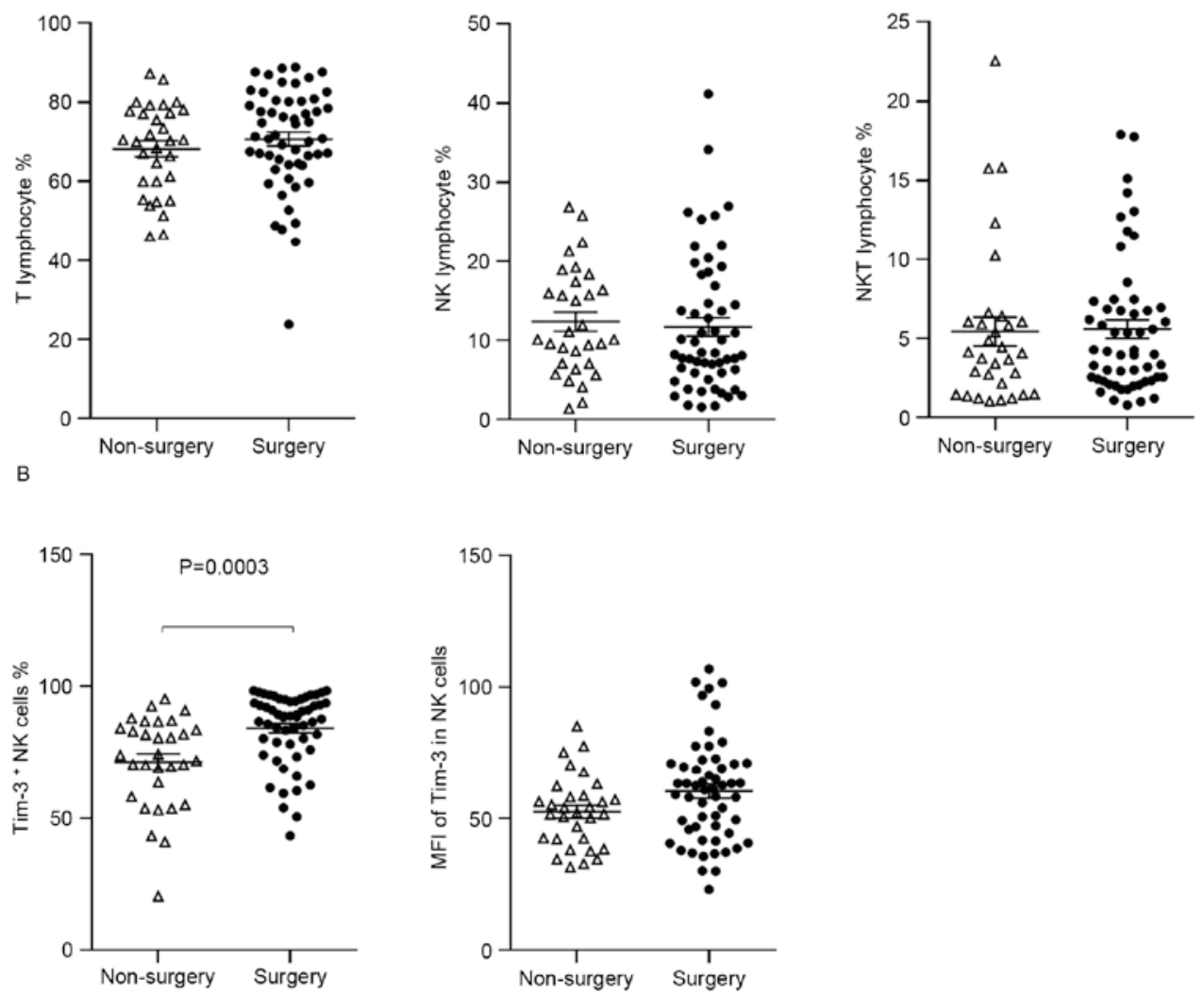

Figure 4. Effects of surgical intervention on lymphocyte subsets and Tim-3+ NK cells. Peripheral blood was obtained from patients that had (n=53) or had not $(\mathrm{n}=36)$ received prior surgery. (A) Percentage of the indicated leukocyte subsets and (B) percentage or MFI of Tim- $3^{+}$NK cells, were assessed by flow cytometry. Each symbol represents a single subject; the mean value is represented by a horizontal line. P-values were determined by Student's t-test. Tim-3, T cell immunoglobulin and mucin protein-3; NK, natural killer; MFI, mean fluorescence intensity; NKT, NK T cells.
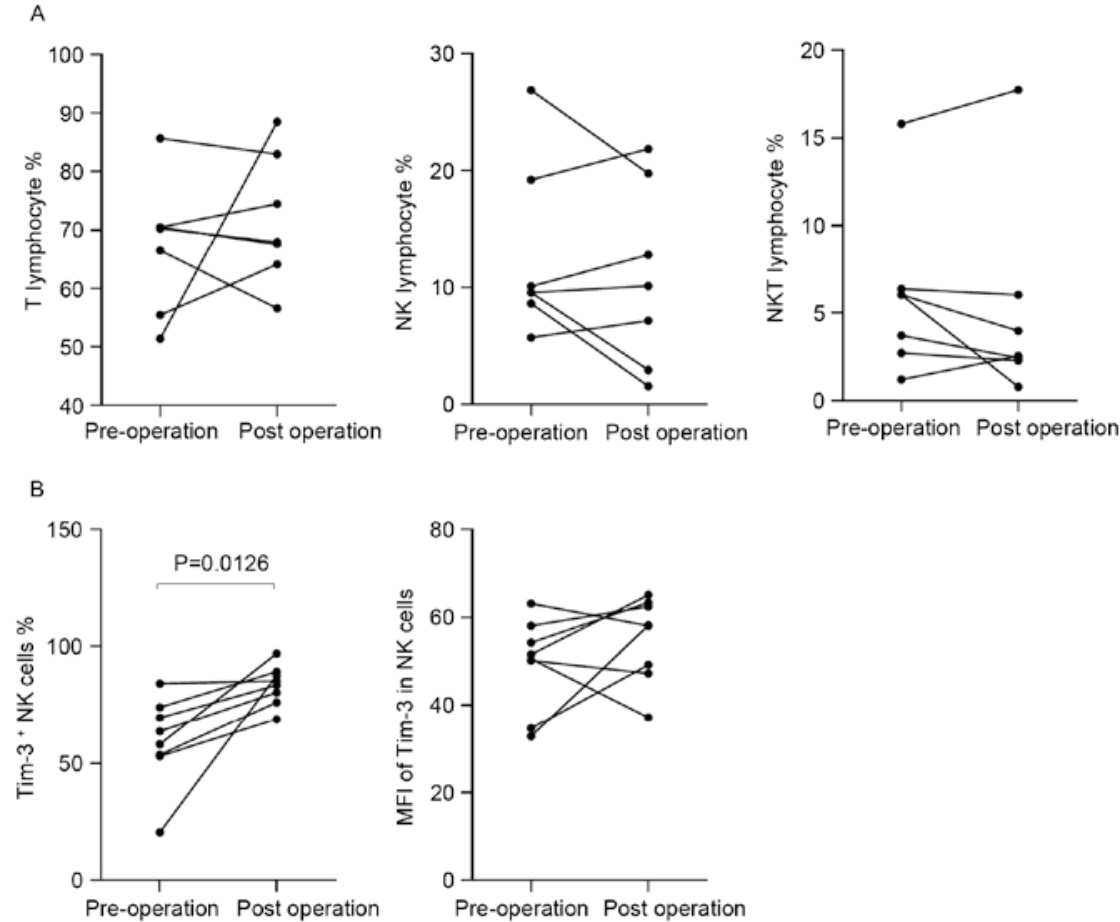

Figure 5. Effects of surgical resection on the percentage of lymphocyte subsets and Tim- $3^{+}$NK cells in CRC patients. Percentage of NK cells and Tim- $3^{+}$ NK cells is indicated for 7 CRC patients pre (0 weeks) and post-resective surgery (1 week). The percentage of (A) NK cells and (B) Tim-3 expression on NK cells was assayed prior to surgery and $\leq 1$ week after surgery. Statistical significance was assessed using a paired Wilcoxon rank sum test with each pre and postoperative data point constituting a pair. Tim-3, T cell immunoglobulin and mucin protein-3; NK, natural killer; CRC, colorectal cancer; NKT, NK T cells; MFI, mean fluorescence intensity. 


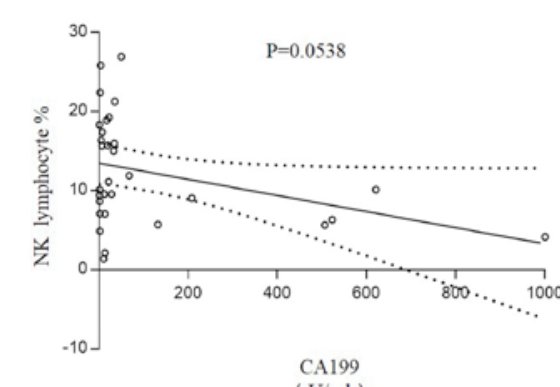

D

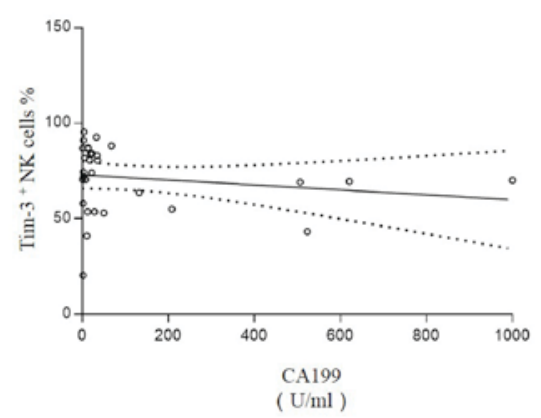

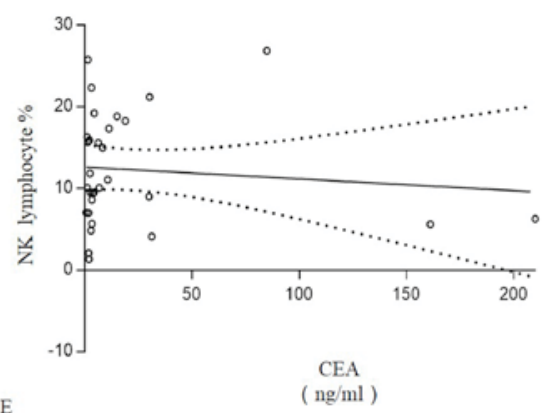

E

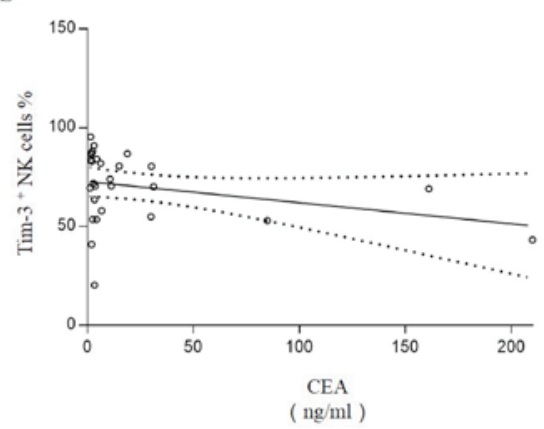

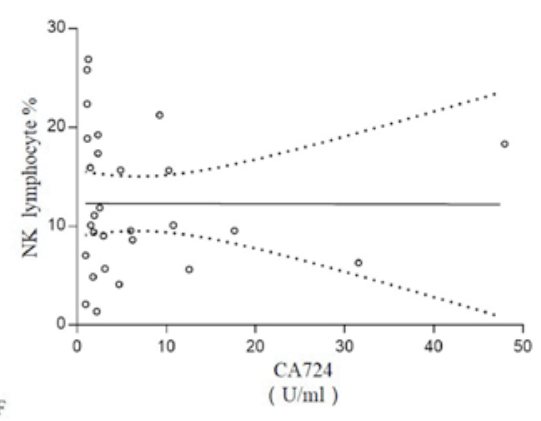

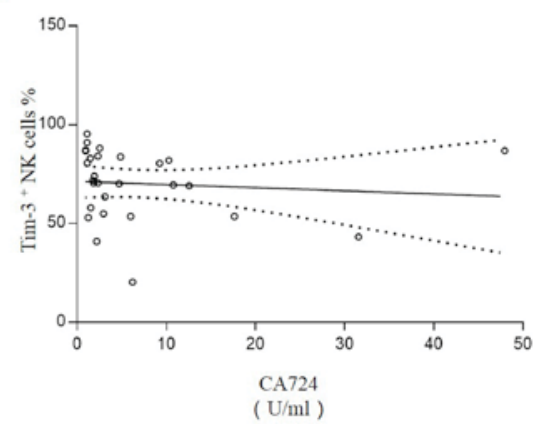

Figure 6. Association between number of NK cells and Tim $-3^{+} \mathrm{NK}$ cells with CRC biomarkers. The relationship between the percentage of NK lymphocytes with the concentration of (A) CA199 (U/ml), (B) CEA (ng/ml) and (C) CA724 (U/ml) is presented. The association between Tim-3 expression on NK cell populations and (D) CA199 (U/ml), (E) CEA (ng/ml) and (F) CA724 (U/ml) is presented. Individual preoperative patient donors are represented by open circles. Least squares linear fit is represented by a thick black line. Statistical significance was determined by a Spearman's rank correlation. Tim-3, T cell immunoglobulin and mucin protein-3; NK, natural killer; CRC, colorectal cancer; NKT, NK T cells; CA, cancer antigen; CEA, carcinoembryonic antigen.

immunotherapy, has been termed 'immune checkpoint blockade'. This strategy is largely driven by the success of therapies targeting cytotoxic T-lymphocyte associated protein-4 and PD-1, and several clinical trials focusing on anti-immune checkpoint antibodies and antagonists are currently underway (12). However, a large number of patients do not currently benefit from this type of cancer therapy (33), and this has catalyzed interest in targeting novel immune checkpoint receptors. Tim-3 has therefore attracted attention as a novel immune checkpoint receptor. Notably, treatment with anti-Tim-3 and anti-PD-ligand 1 antibodies significantly limited tumor growth in vivo (34). In CRC, previous research demonstrated significantly higher levels of circulating Tim- $3^{+} \mathrm{PD}-1^{+} \mathrm{CD} 8^{+} \mathrm{T}$ cells, indicating that Tim-3 blockage may be a potential therapeutic approach for CRC patients (13). However, given the expression of Tim-3 on other immune cells, including NK cells, Tim-3 therapy should be cautious, and the choice of targeted immune checkpoint should be founded on knowledge of the immune system. The present study also demonstrated that surgical resection of the primary tumor rapidly reverses Tim-3 expression in NK cell populations, which has significant implications for the timing of Tim-3 based therapies. However, this will require large and properly controlled clinical studies to verify and screen novel therapeutics.

The present study indicated that reduced NK cell Tim-3 expression is associated with CRC progression and presentation of poor prognostic clinical parameters. For the first time, Tim-3 has been demonstrated as a bioactivity marker, which is expressed in NK cells from patients with CRC. Tim-3 may serve as a serum biomarker, which could predict disease progression, and potentially prove useful in identifying patients likely to benefit from Tim-3-based therapies.

\section{Acknowledgements}

This work was supported by grants from the National Natural Science Foundation of China (grant nos. 31470885, 31300752, 31270971, 81300510, 30901326 and 81072406).

\section{References}

1. Dalgleish AG and O'Byrne KJ: Chronic immune activation and inflammation in the pathogenesis of AIDS and cancer. Adv Cancer Res 84: 231-276, 2002.

2. Shibata M, Nezu T, Kanou H, Abe H, Takekawa M and Fukuzawa M: Decreased production of interleukin-12 and type 2 immune responses are marked in cachectic patients with colorectal and gastric cancer. J Clin Gastroenterol 34: 416-420, 2002.

3. Pagès F, Berger A, Camus M, Sanchez-Cabo F, Costes A, Molidor R, Mlecnik B, Kirilovsky A, Nilsson M, Damotte D, et al: Effector memory $\mathrm{T}$ cells, early metastasis, and survival in colorectal cancer. N Engl J Med 353: 2654-2666, 2005.

4. Tachibana T, Onodera H, Tsuruyama T, Mori A, Nagayama S, Hiai $\mathrm{H}$ and Imamura M: Increased intratumor Valpha24-positive natural killer T cells: A prognostic factor for primary colorectal carcinomas. Clin Cancer Res 11: 7322-7327, 2005.

5. Chen ZY, Raghav K, Lieu CH, Jiang ZQ, Eng C, Vauthey JN, Chang GJ, Qiao W, Morris J, Hong D, et al: Cytokine profile and prognostic significance of high neutrophil-lymphocyte ratio in colorectal cancer. Br J Cancer 112: 1088-1097, 2015.

6. Ling L, Zhao P, Yan G, Chen M, Zhang T, Wang L and Jiang Y: The frequency of Th17 and Th22 cells in patients with colorectal cancer at pre-operation and post-operation. Immunol Invest 44: 56-69, 2015. 
7. Pawa N, Arulampalam $\mathrm{T}$ and Norton JD: Screening for colorectal cancer: Established and emerging modalities. Nat Rev Gastroenterol Hepatol 8: 711-722, 2011.

8. Murdoch C, Muthana M, Coffelt SB and Lewis CE: The role of myeloid cells in the promotion of tumour angiogenesis. Nat Rev Cancer 8: 618-631, 2008.

9. Shi C and Pamer EG: Monocyte recruitment during infection and inflammation. Nat Rev Immunol 11: 762-774, 2011.

10. Diederichsen AC, Hjelmborg Jv, Christensen PB, Zeuthen J and Fenger C: Prognostic value of the $\mathrm{CD}^{+} / \mathrm{CD}^{+}$ratio of tumour infiltrating lymphocytes in colorectal cancer and HLA-DR expression on tumour cells. Cancer Immunol Immunother 52: 423-428, 2003

11. Hua W, Yuan A, Zheng W, Li C, Cui J, Pang Z, Zhang L, Li Z, Goll R and Cui G: Accumulation of FoxP $3^{+} \mathrm{T}$ regulatory cells in the tumor microenvironment of human colorectal adenomas. Pathol Res Pract 212: 106-112, 2016.

12. Singh PP, Sharma PK, Krishnan G and Lockhart AC: Immune checkpoints and immunotherapy for colorectal cancer. Gastroenterol Rep(Oxf) 3: 289-297, 2015.

13. Xu B, Yuan L, Gao Q, Yuan P, Zhao P, Yuan H, Fan H, Li T, Qin P, Han L, et al: Circulating and tumor-infiltrating Tim-3 in patients with colorectal cancer. Oncotarget 6: 20592-21603, 2015.

14. Kuchroo VK, Dardalhon V, Xiao S and Anderson AC: New roles for TIM family members in immune regulation. Nat Rev Immunol 8: 577-580, 2008.

15. Kong Y, Zhang J, Claxton DF, Ehmann WC, Rybka WB, Zhu L, Zeng H, Schell TD and Zheng H: PD-1(hi)TIM-3(+) T cells associate with and predict leukemia relapse in AML patients post allogeneic stem cell transplantation. Blood Cancer J 5: e330, 2015.

16. Cai C, Xu YF, Wu ZJ, Dong Q, Li MY, Olson JC, Rabinowitz YM, Wang LH and Sun Y: Tim-3 expression represents dysfunctional tumor infiltrating T cells in renal cell carcinoma. World J Urol 34 561-567, 2016.

17. da Silva IP, Gallois A, Jimenez-Baranda S, Khan S, Anderson AC Kuchroo VK, Osman I and Bhardwaj N: Reversal of NK-cell exhaustion in advanced melanoma by Tim-3 blockade. Cancer Immunol Res 2: 410-422, 2014

18. Xu L, Huang Y, Tan L, Yu W, Chen D, Lu C, He J, Wu G, Liu X and Zhang Y: Increased Tim-3 expression in peripheral NK cells predicts a poorer prognosis and Tim-3 blockade improves NK cell-mediated cytotoxicity in human lung adenocarcinoma. Int Immunopharmacol 29: 635-641, 2015

19. Edge SB, Byrd SR, Compton CC, Fritz AG, Greene FL and Trotti A (eds): AJCC Cancer Staging Manual. 7th edition. Springer-Verlag, New York, NY, pp143-164, 2010.

20. Golden-Mason L, Waasdorp Hurtado CE, Cheng L and Rosen HR: Hepatitis C viral infection is associated with activated cytolytic natural killer cells expressing high levels of T cell immunoglobulin- and mucin-domain-containing molecule-3. Clin Immunol 158: 114-125, 2015.

21. Anderson AC: Tim-3, a negative regulator of anti-tumor immunity. Curr Opin Immunol 24: 213-216, 2012.
22. Imai K, Matsuyama S, Miyake S, Suga K and Nakachi K: Natural cytotoxic activity of peripheral-blood lymphocytes and cancer incidence: An 11-year follow-up study of a general population. Lancet 356: 1795-1799, 2000

23. Koda K, Saito N, Oda K, Seike K, Kondo E, Ishizuka M, Takiguchi N and Miyazaki M: Natural killer cell activity and distant metastasis in rectal cancers treated surgically with and without neoadjuvant chemoradiotherapy. J Am Coll Surg 197: 254-260, 2003

24. Kondo E, Koda K, Takiguchi N, Oda K, Seike K, Ishizuka M and Miyazaki M: Preoperative natural killer cell activity as a prognostic factor for distant metastasis following surgery for colon cancer. Dig Surg 20: 445-451, 2003.

25. Vivier E, Ugolini S, Blaise D, Chabannon C and Brossay L: Targeting natural killer cells and natural killer T cells in cancer. Nat Rev Immunol 12: 239-252, 2012.

26. Ndhlovu LC, Lopez-Vergès S, Barbour JD, Jones RB, Jha AR, Long BR, Schoeffler EC, Fujita T, Nixon DF and Lanier LL: Tim-3 marks human natural killer cell maturation and suppresses cell-mediated cytotoxicity. Blood 119: 3734-3743, 2012.

27. Gleason MK, Lenvik TR, McCullar V, Felices M, O'Brien MS, Cooley SA, Verneris MR, Cichocki F, Holman CJ, Panoskaltsis-Mortari A, et al: Tim-3 is an inducible human natural killer cell receptor that enhances interferon gamma production in response to galectin-9. Blood 119: 3064-3072, 2012.

28. Halama N, Braun M, Kahlert C, Spille A, Quack C, Rahbari N, Koch M, Weitz J, Kloor M, Zoernig I, et al: Natural killer cells are scarce in colorectal carcinoma tissue despite high levels of chemokines and cytokines. Clin Cancer Res 17: 678-689, 2011.

29. Xu LY, Chen DD, He JY, Lu CC, Liu XG, Le HB, Wang CY and Zhang YK: Tim-3 expression by peripheral natural killer cells and natural killer T cells increases in patients with lung cancer-reduction after surgical resection. Asian Pac J Cancer Prev 15: 9945-9948, 2014

30. Jost S, Moreno-Nieves UY, Garcia-Beltran WF, Rands K, Reardon J, Toth I, Piechocka-Trocha A, Altfeld $\mathrm{M}$ and Addo MM: Dysregulated Tim-3 expression on natural killer cells is associated with increased Galectin-9 levels in HIV-1 infection. Retrovirology 10: 74, 2013.

31. Wang YR, Yan JX and Wang LN: The diagnostic value of serum carcino-embryonic antigen, alpha fetoprotein and carbohydrate antigen 19-9 for colorectal cancer. J Cancer Res Ther 10 (Suppl): S307-S309, 2014.

32. Zhu Z, Chen Z, Chen C, Yang Z, Xuan W, Hou Y, Zuo Y and Ren S: Opposite variation tendencies of serum CA724 levels in patients with colon and rectal carcinoma. Mol Clin Oncol 2: 139-145, 2014.

33. Haddad AQ and Margulis V: Tumour and patient factors in renal cell carcinoma-towards personalized therapy. Nat Rev Urol 12: 253-262, 2015.

34. Sakuishi K, Apetoh L, Sullivan JM, Blazar BR, Kuchroo VK and Anderson AC: Targeting Tim-3 and PD-1 pathways to reverse T cell exhaustion and restore anti-tumor immunity. J Exp Med 207: 2187-2194, 2010. 